\title{
Comparative study of programmed labor and traditional management of labor
}

\author{
Nitin S. Kshirsagar*, Sanjay S. Patil, Anand V. Karale
}

Department of Obstetrics \& Gynecology, Krishna Institute of Medical Sciences, Karad, Maharashtra, India

Received: 29 March 2013

Accepted: 14 April 2013

*Correspondence:

Dr. Nitin S. Kshirsagar,

E-mail: nkshirsagar49@yahoo.com

(C) 2013 Kshirsagar NS et al. This is an open-access article distributed under the terms of the Creative Commons Attribution License, which permits unrestricted use, distribution, and reproduction in any medium, provided the original work is properly cited.

\section{ABSTRACT}

Background: Prolongation of labor leads to dehydration, ketoacidosis, infection, fetal asphyxia. Programmed labor aims at reducing the duration of labor, labor pain and incidence of cesarean section with improved maternal and neonatal outcome.

\section{Aims and Objectives:}

1) To evaluate the effect of programmed labor on duration of labor.

2) To assess efficacy of analgesics in reducing pain of labor.

3) To find out maternal and neonatal complications.

4) To study impact of programmed labor on LSCS rates.

Methods: Prospective randomized study of primigravida in active labor (after $4 \mathrm{~cm}$ cervical dilatation) for which 100 women were selected for programmed labor (cases) and 100 women were selected for traditional management of labor (controls). Cases were subjected to interventions to improve uterine contractions (ARM, Dinoprostone tablets, and Oxytocin drip), to facilitate cervical dilatation (Inj. Drotaverine), to relieve labor pains (Inj. Pentazocine \& Diazepam). All labors were monitored by partogram.

Results: Programmed labor reduced duration of first and second stage of labor. There was faster cervical dilatation $(1.8 \mathrm{~cm} /$ hour against $1.2 \mathrm{~cm} /$ hour$)$. Majority of the patients had better pain relief. There was no impact on LSCS rates Conclusions: Programmed labor significantly reduced duration of labor with good pain relief without compromising maternal and fetal/neonatal safety. But it had no impact on LSCS rates.

Keywords: Programmed labor, Duration of labor, Pain relief

\section{INTRODUCTION}

Although labor is a physiological process, its prolongation can result in dehydration, ketoacidosis, infection, fetal asphyxia, increased operative intervention.

Earlier dictum was "Watchful expectancy and masterly inactivity".

O Driscoll ${ }^{1}$ totally changed this concept by introducing active management of labor.

Dr. Daftary et $\mathrm{al}^{2}$ developed the protocol of programmed labor in India.
It is based on four pillars:

1) Oxytocics to ensure adequate uterine contractions.

2) Antispasmodics to facilitate cervical dilatation.

3) Analgesics to provide optimum pain relief.

4) Partogram to assess progress of labor.

We adopted Dr. Daftary protocol with some modifications in the present study. Programmed labor protocol was compared with traditional management in primigravida. 


\section{Aims and Objectives}

1) To evaluate the effect of programmed labor on duration of labor.

2) To assess efficiency of analgesics in reducing severity of labor pains.

3) To find out any maternal and fetal/neonatal complications.

4) To study impact of programmed labor on LSCS rates.

\section{METHODS}

The present prospective randomized study was undertaken at Krishna Institute of Medical Sciences Karad (India). It was approved by ethical committee of the institute.

The patients in active labor were divided into two groups by simple randomization.

Group I: 100 (cases) for programmed labor.

Group II: 100 (controls) for traditional management of labor.

Total sample size was 200 primigravidas.

\section{Inclusion criteria}

1) Full term primigravida

2) Cervical dilatation $>4 \mathrm{~cm}$

3) Singleton pregnancy

4) No other Obstetrical complications

\section{Exclusion criteria}

1) Malpresentations

2) Previous LSCS

3) Obstetrical complications (PIH, IUGR Postdate pregnancy)

4) Patients of asthma, Heart disease, Hypersensitivity to prostaglandins

\section{Protocol of Programmed labor}

1) At $4 \mathrm{~cm}$ of cervical dilatation, following steps were taken.

a) ARM

b) Tab dinoprostone $0.5 \mathrm{mg}$ in cervix, repeated 2 hourly if required, for 4 doses

c) IV Oxytocin drip if contractions were not optimum in 4 hours

2) IV $6 \mathrm{mg}$ Pentazocine diluted in $10 \mathrm{ml}$ normal saline and IV Diazepam $2 \mathrm{mg}$ diluted in $10 \mathrm{ml}$ normal saline slowly were administered through separate syringes to initiate pain relief.
The drugs were repeated every 2 hours if required.

Pain relief was assessed on a scale.

3) IV Drotaverine (1 ampoule) was injected at $4 \mathrm{~cm}$ cervical dilatation and was repeated every 2 hours for maximum 3 doses.

4) IV DNS/DLR was started if and when required.

5) Partogram was used to assess progress of labor.

\section{Control group}

Partographic monitoring of labor was done.

Inj Tramadol $50 \mathrm{mg}$ IM was used for pain relief.

Pentazocine, Diazepam, Drotaverine were not used.

\section{Assessment}

Following conditions were recorded:

- Duration of first and second stage of labor

- Rate of cervical dilatation

- Level of analgesia using following scale 0 :- No pain relief

1:- Mild pain relief

2:- Moderate pain relief

3:- Excellent pain relief

- Mode of delivery

- Maternal complications( Infection, Genital injuries, PPH, Side effects of drugs)

- Fetal/Neonatal complications (Fetal distress, IUD, Trauma)

- APGAR score at 1 minute and at 5 minutes

\section{RESULTS}

1) The duration of active phase of labor was significantly reduced ( 3.42 hours in cases \& 4.71 hrs in controls, $\mathrm{p}<0.0001$ ).

2) The duration of II stage of labor was $27.8 \mathrm{~min}$ in cases \& $34.2 \mathrm{~min}$ in controls $(\mathrm{p}<0.0004)$.

3) The rate of cervical dilatation was $1.80 \mathrm{~cm} / \mathrm{hr}$ in cases and $1.26 \mathrm{~cm} / \mathrm{hr}$ in controls $(\mathrm{p}<0.0001)$ which is significant.

4) Majority of the patients in both groups delivered vaginally ( $89 \%$ in study group \& $88 \%$ in controls).

5) $73 \%$ patients in study group and $22 \%$ in control group had pain relief. It is statistically significant.

6) The cases had significantly more drug related side effects like nausea, vomiting, drowsiness, that subsided after 12 hours. 
7) There was significantly higher frequency of hypertonic contractions $(5 \%)$ in cases than in controls $(1 \%)$.

8) There were no significant fetal/neonatal complications in either group.

Table 1: Age wise distribution of patients.

\begin{tabular}{|lll|}
\hline $\begin{array}{l}\text { Age in } \\
\text { years }\end{array}$ & $\begin{array}{l}\text { Cases } \\
(\mathbf{n}=\mathbf{1 0 0})\end{array}$ & $\begin{array}{l}\text { Controls } \\
(\mathbf{n}=\mathbf{1 0 0})\end{array}$ \\
\hline$<20$ & 41 & 28 \\
\hline $21-25$ & 51 & 65 \\
\hline $26-30$ & 8 & 7 \\
\hline$>30$ & 0 & 0 \\
\hline
\end{tabular}

Most of the patients in both groups were $<25$ years.

Table 2: Duration of stages of labor.

\begin{tabular}{|llll|}
\hline & Active phase & II stage & III stage \\
\hline Case & 3.42 hours & $27.8 \mathrm{~min}$ & $4.46 \mathrm{~min}$ \\
\hline Control & 4.7 hours & $34.2 \mathrm{~min}$ & $4.55 \mathrm{~min}$ \\
\hline
\end{tabular}

There was statistically significant difference in the duration of active phase \& II stage of labor.

Table 3: Rate of cervical dilatation in active phase.

\begin{tabular}{|lll|}
\hline & \multicolumn{2}{l|}{ Rate of cervical dilatation } \\
\hline Cases & $1.80 \mathrm{~cm} / \mathrm{hr}$ & Cases \\
\hline Controls & $1.26 \mathrm{~cm} / \mathrm{hr}$ & Controls \\
\hline
\end{tabular}

Cervical dilatation was significantly faster in cases $(\mathrm{p}<0.0001)$.

Table 4: Pain relief score.

\begin{tabular}{|llll|l|}
\hline Score & Cases & Percentage & Controls & Percentage \\
\hline 3 & 0 & 0 & 0 & 0 \\
\hline 2 & 26 & $26 \%$ & 0 & $0 \%$ \\
\hline 1 & 47 & $47 \%$ & 22 & $22 \%$ \\
\hline 0 & 27 & $27 \%$ & 78 & $78 \%$ \\
\hline
\end{tabular}

There was better pain relief in cases $(73 \%)$ than in controls $(22 \%)$.

Table 5: Mode of delivery.

\begin{tabular}{|lll|ll|}
\hline Mode & $\begin{array}{l}\text { Cases } \\
(\mathbf{n = 1 0 0})\end{array}$ & Percentage & Controls & Percentage \\
\hline FTND & 88 & $88 \%$ & 86 & $86 \%$ \\
\hline Ventouse & 1 & $1 \%$ & 2 & $2 \%$ \\
\hline Forceps & 0 & $0 \%$ & 0 & $0 \%$ \\
\hline LSCS & 11 & $11 \%$ & 12 & $12 \%$ \\
\hline
\end{tabular}

Most of the patients in both groups delivered vaginally.

Table 6: Complications \& side effects.

\begin{tabular}{|lll|}
\hline Complications & Cases & Controls \\
\hline Nausea & 6 & 3 \\
\hline Vomiting & 6 & 2 \\
\hline Drowsiness & 4 & 0 \\
\hline Tachycardia & 4 & 3 \\
\hline $\begin{array}{l}\text { Hypertonic } \\
\text { contractions }\end{array}$ & 5 & 1 \\
\hline Cervical/Vaginal tears & 6 & 4 \\
\hline Rupture uterus & 0 & 0 \\
\hline
\end{tabular}

Cases had more side effects than in controls which are related to drugs.

Table 7: APGAR score.

\begin{tabular}{|lll|}
\hline APGAR Score & Cases & Controls \\
\hline At $1 \min (4-5)$ & 5 & 7 \\
\hline At $1 \min (6-7)$ & 95 & 93 \\
\hline At $5 \min (6-7)$ & 5 & 7 \\
\hline At $5 \min (8-9)$ & 95 & 93 \\
\hline
\end{tabular}

APGAR score was comparable in both groups.

\section{DISCUSSION}

Programmed labor protocol was designed for shorter, safer and relatively painless vaginal delivery, making it a joyful and satisfactory event.

\section{Duration of labor}

In our study, mean duration of active phase of labor in primi was3.42 hours (cases) and 4.73 hours (controls). It was statistically significant $(\mathrm{p}<0.0001)$.

Mean duration of II stage of labor was 28 minutes (cases) and 34 minutes (controls) which was statistically significant $(\mathrm{p}<0.0004)$.

Dr. Daftary et $\mathrm{al}^{3}$ reported active phase duration to be 3.5 hours in cases and that of II stage of labor to be 26 minutes.

Dr. Chauhan et $\mathrm{al}^{4}$ found duration of first stage of labor to be 3.4 hours.

\section{Cervical dilatation}

The cervix dilated at a faster rate $(1.8 \mathrm{~cm} / \mathrm{hr})$ in programmed labor than in controls $(1.26 \mathrm{~cm} / \mathrm{hr})$. It resulted in shorter labours. 
Veronica et $\mathrm{al}^{5}$ noticed that rate of cervical dilatation was nearly double $(2.3 \mathrm{~cm} / \mathrm{hr})$ in subjects and $(1.2 \mathrm{~cm} / \mathrm{hr})$ in controls.

According to Mishra et $\mathrm{al}^{6}$ and Singh et $\mathrm{al}^{7}$, it is the effect of Drotaverine.

\section{Pain relief}

Pain relief plays a vital role in maternal well being. Pain and fear retard the progress of labor. It prevents maternal hyperventilation, undue muscular efforts and exhaustion. Hence, pain relief was one of the important objectives of the study.

We observed that $73 \%$ cases had pain relief. Out of them $47 \%$ experienced excellent pain relief while in controls, only $22 \%$ had pain relief.

Veronica et $\mathrm{al}^{5}$ reported total pain relief in $70 \%$ cases.

Meena Jyoti et $\mathrm{al}^{8}$ noticed that $54 \%$ achieved good and $32 \%$ achieved moderate pain relief.

\section{LSCS rates}

Programmed labor did not have any significant impact on LSCS rates. Majority of the patients in both groups delivered vaginally ( $88 \%$ in cases $\& 86 \%$ in controls).

This was in accordance with the findings of Veronica ${ }^{5}$, Daftary $^{3}$, and Jyoti ${ }^{8}$.

\section{Maternal outcome}

None of the patients had any major complications of labor.

In programmed labor group, drug related side effects like nausea, vomiting, drowsiness, tachycardia were seen. All the side effects subsided by 12 hours after delivery.

Five cases developed hypertonic uterine contractions. Only one of them required LSCS for fetal distress.

Veronica et $\mathrm{al}^{5}$ had similar findings. Tachycardia $(80 \%)$ was the commonest side effect followed by nausea and vomiting (10\%).

\section{Neonatal outcome}

Most of the babies in both groups had good Apgar score (>7 in $95 \%$ cases \& in $93 \%$ controls).

\section{CONCLUSIONS}

Programmed labor group had:

- Faster cervical dilatation

- Shorter labors

- Excellent pain relief

- No impact on LSCS rates

- No compromise on Maternal or Neonatal safety

\section{ACKNOWLEDGEMENTS}

We thank Medical Director, Krishna Institute of Medical Sciences Karad (India) for allowing us to use and publish data related to patients.

\section{Funding: No funding sources}

Competing interests: None

Ethical approval: The study was approved by the ethical committee of the institute

\section{REFERENCES}

1. O Driscoll, Foley M. Active management of labor as an alternative to cesarean section for dystocia. Obstet Gynecol 1984;63:485-90.

2. Daftary SN, Desai SV, Thanawala U, et al. Programmed labor- an indigenously developed protocol of labor management. Int J Gynecol Obst Ind 2003;6:47-9.

3. Daftary SN, Desai SV, Thanawala U, et al. Programmed labor- Indigenous protocol to optimize labor outcome. South Asian Federation of Obstet Gynecol 2009;1:61-4.

4. Chauhan R, Gupta AA. A clinical study of programmed labor \& its outcome. J Obstet Gynecol Family Welfare 2003;5:8-9.

5. Veronica Irene, Vaneet Kaur. Programmed labor for optimizing labor \& delivery. JK Science 2008;10:62-4.

6. Mishra SL, Toshniwal A. Effect of Drotaverine HCL on cervical dilatation in labor, a comparison with Valethamate bromide. J Obstet Gynecol India 2002;52:76.

7. Singh KC, Jain P, Goel N. Drotaverine hydrochloride for augmentation of labor. Int $\mathrm{J}$ Gynaecol Obstet 2004;84:17-22.

8. Jyoti M, Singhal P, Choudhary D. Programmed labor. J Obstet Gynecol India 2006;56:53-5.

DOI: $10.5455 / 2320-1770 . i j \operatorname{cog} 20130620$

Cite this article as: Kshirsagar NS, Patil SS,

Karale AV. Comparative study of programmed

labor and traditional management of labor. Int $\mathbf{J}$

Reprod Contracept Obstet Gynecol 2013;2:209-12. 